However, the ESSENCE ensemble simulates lower warming trends than the observations in the area where the return times of autumn 2006 are high. The other four models that we considered also show lower than observed trends. If we believe the model trends rather than the observed ones, the return times would be increased to thousands of years.

The 17 ensemble members in ESSENCE enable us to investigate the changes in variability as a function of time. The extreme value distributions of the model surface air temperature at De Bilt have been computed for 30-year intervals, each of which contains 510 years of data. These five curves are shown in Figure 3. There is a clear vertical shift over time: the warming trend. However, there is no indication of an increase in the slopes that would make extremely warm autumn temperatures more likely. This result was confirmed using three other climate models, for which a comparison between the $20^{\text {th }}$ and $22^{\text {nd }}$ centuries could be made. None of these show an increase in the tail of the distribution at the grid point corresponding to De Bilt.
We conclude that current climate models show neither a faster increase in the mean temperature nor an increase in variability that would reduce the return times of autumn 2006.

\section{Conclusions}

The autumn of 2006 was extraordinarily warm in large parts of Europe, with temperatures up to $4^{\circ} \mathrm{C}$ above the 1961-1990 norms. Assuming an unchanging climate, this would correspond to return times of 10,000 years and more.

Global warming has made a warm autumn like the one observed in 2006 much more likely by shifting the temperature distribution to higher values. Taking only this mean warming into account, the best estimate of the return time of the observed temperatures in 2006 is still in excess of 200 years over large parts of Europe.

Current climate models already underestimate the observed mean warming in Europe relative to global warming before 2006. They also do not show an additional increase of the warm tail of the distribution as the climate warms. Either the autumn of 2006 was a very rare event, or these climate models do not give the correct change in temperature distribution as the temperature rises, due to missing feedbacks.

\section{References}

Jungclaus, J.H., Keenlyside, N., Botzet, M., Haak, H., Luo, J.-J., Latif, M., Marotzke, J., Mikolajewicz, U. and Roeckner, E., 2006: Ocean circulation and tropical variability in the coupled model ECHAM5/ MPI-OM, Journal of Climate, 19: 3952-3972, doi:10.1175/ JCLI3827.1.

Luterbacher, J., Liniger, M.A., Menzel, A., Estrella, N., Della-Marta, P.M., Pfister, C., Rutishauser, T. and Xoplaki, E., 2007: The exceptional European warmth of autumn 2006 and winter 2007: Historical context, the underlying dynamics and its phenological impacts, Geophysical Research Letters, 34: L12704, doi:10.1029/2007GL029951.

Schär, C. and Jendritzky, G., 2004: Hot news from summer 2003, Nature, 432: 559-560.

van Oldenborgh, G.J., 2007: How unusual was autumn 2006 in Europe? Climate of the Past, 3: 659-668, www.clim-past. net/3/659/2007/

van Ulden, A.P. and van OIdenborgh, G.J., 2006: Large-scale atmospheric circulation biases and changes in global climate model simulations and their importance for climate change in Central Europe, Atmospheric Chemistry and Physics, 6: 863-881.

For full references please consult:

www.pages-igbp.org/products/newsletter/ref2008_2.html

\title{
Risk prediction of Canadian wildfires
}

\author{
Manfred Mudelsee ${ }^{1,2}$ and Martin P. Girardin ${ }^{3}$ \\ ${ }^{1}$ Climate Risk Analysis, Hannover, Germany; mudelsee@mudelsee.com \\ ${ }^{2}$ Alfred Wegener Institute for Polar and Marine Research, Bremerhaven, Germany; mudelsee@climate-risk-analysis.com \\ ${ }^{3}$ Canadian Forest Service, Natural Resources Canada, Quebec
}

Wildfires in Canada burn on average more than $2 \times 10^{4} \mathrm{~km}^{2}$ of forest per year (Fig. 1) (Stocks et al., 2003), with accompanying economic losses. In years of high fire activity in Canada, the amount of carbon released into the atmosphere by wildfires approaches levels comparable to industrial carbon emissions (Amiro et al., 2001). Predicting the risk (probability) of such extreme events in the regional domain and on mid-term timescales (decades) can serve forest managers, climate and carbon modelers, and the insurance industry. Several requirements have to be met to achieve prediction skill and reliability: data records of sufficient length, climate models able to reproduce observed data properties, and a robust statistical risk estimation method. Results from wildfire records (observed, proxy, and models) analyzed with kernel estimation (a nonparametric smoothing approach), reveal that by the end of the $21^{\text {st }}$ century, wildfire risk for Canada may rise and eventually exceed the high levels observed in the previous two centuries.

\section{Data: Wildfire proxy records}

Records of directly observed wildfire events are sparse and cover too short a time frame for risk analysis of extreme (i.e., rare) events. This study considered only large (> $200 \mathrm{ha}$ ) fires, from the Large Fire Data Base (Stocks et al., 2003) to achieve a

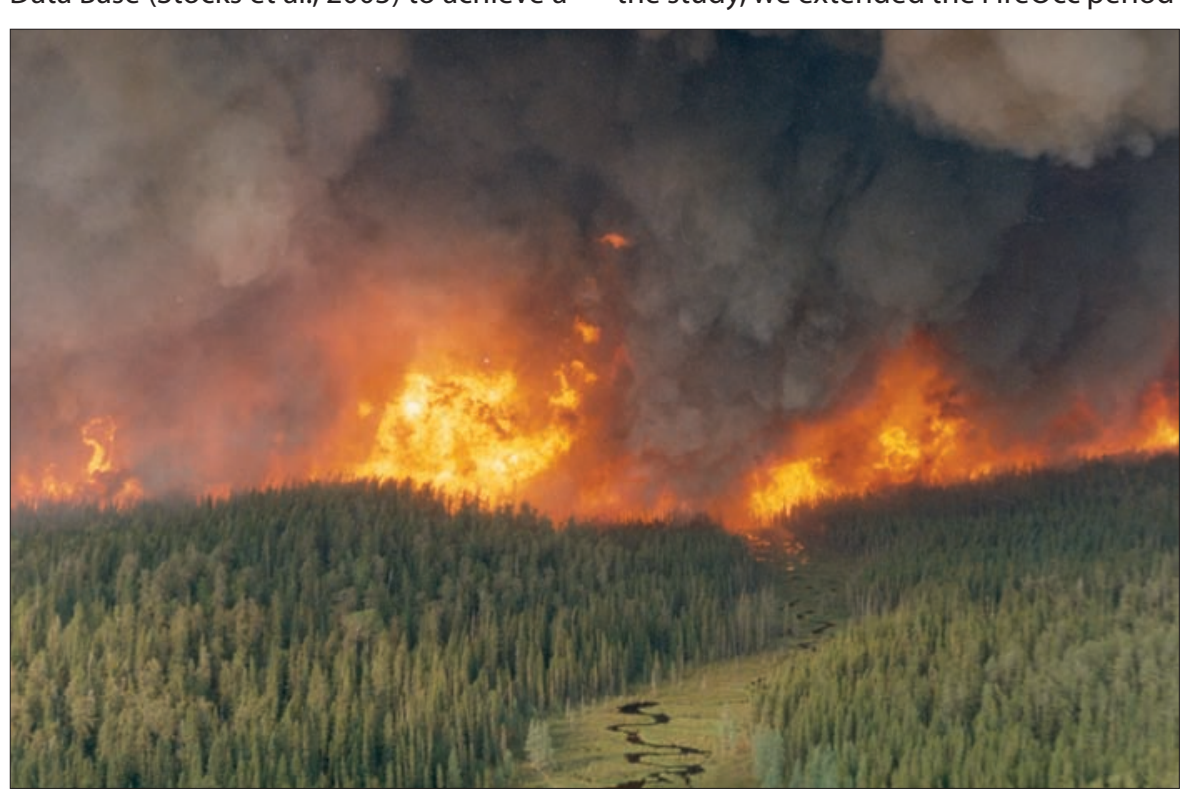

Figure 1: Red Lake forest fire, Ontario (photo by Brian Stocks, Canadian Forest Service). high degree of data homogeneity over the observation period, 1959 to 1998 . These large fires account for $97 \%$ of the total area burnt in Canada. The variable "FireOcc" represents the number of large fires per year. To broaden the temporal coverage of the study, we extended the FireOcc period 


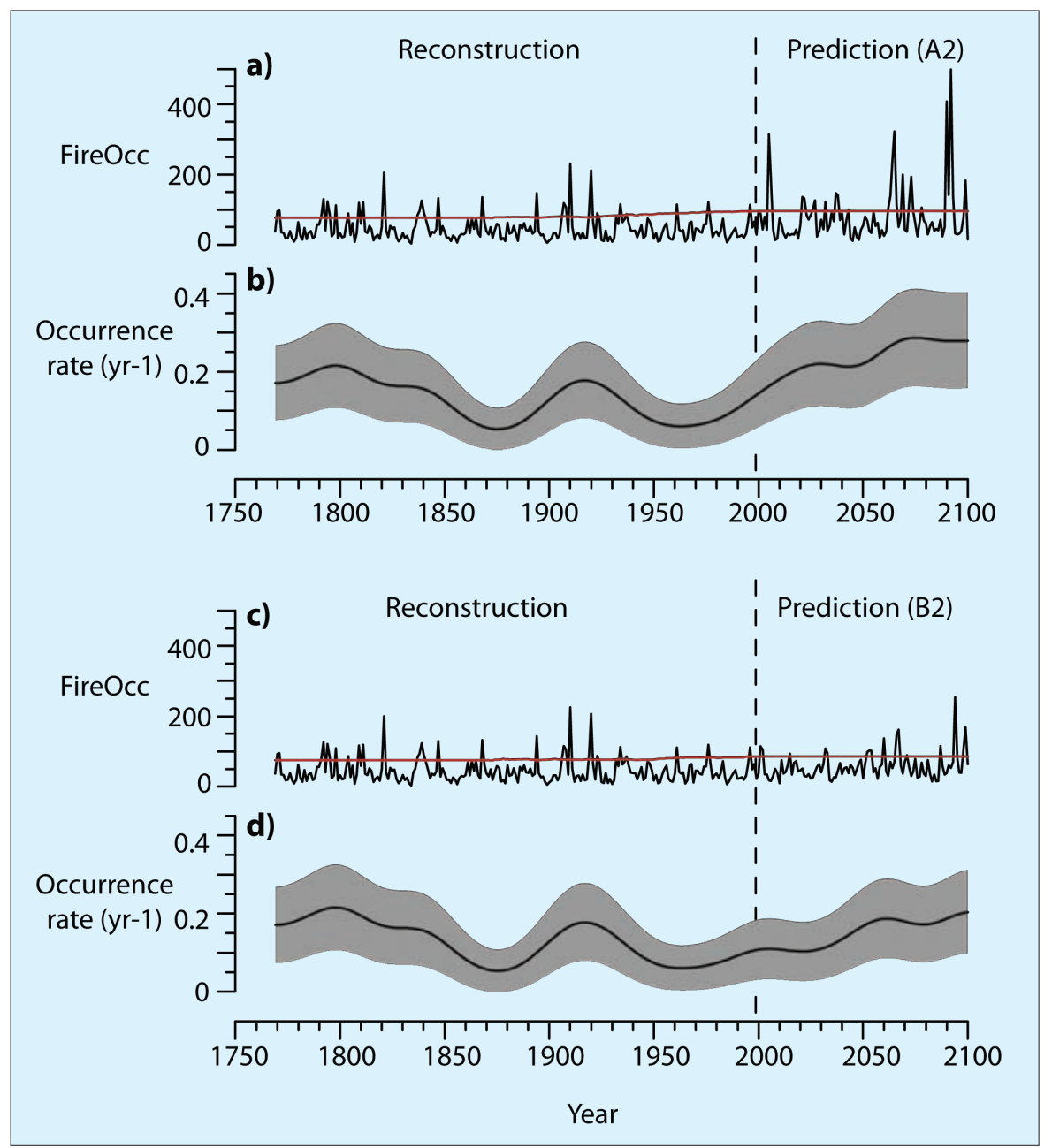

Figure 2: Past and future wildfire risk in Canada. $(\boldsymbol{a}, \boldsymbol{c})$ FireOcc - number of large (> 200 ha) forest fires per year, reconstructed (1769-1998) from tree ring measurements via the Drought Code, or modeled for greenhouse gas emission scenarios A2 and B2. Red line indicates threshold for extreme fire years and is defined by robust measures of trend and variability (CLIM-X-DETECT software with parameters $z=2.5$ and $k=100$, Mudelsee (2006)). $(\boldsymbol{b}, \boldsymbol{d})$ Wildfire risk estimated as rate of occurrence (solid black line) of extreme fire years via a kernel approach (CALIZA software with bandwidth parameter $h=15$ a, developed after Mudelsee et al. $(2003,2004)$ ). Bootstrap simulations ( $n$ sim $=10000$ ) yield $90 \%$ confidence bands (grey shading) for risk estimates.

back to 1769 using a two-stage proxy approach based on the Canadian Drought Code (DC). This index (Turner, 1972) is the daily moisture content of organic matter (bulk density $138.9 \mathrm{~kg} / \mathrm{m}^{3}$ ) for an average organic matter thickness of $18 \mathrm{~cm}$.

In the first stage of analysis, measured records of tree ring thickness were used to infer DC. The tree ring database (126 replicated records) covered the Canadian Boreal Shield (Girardin et al., 2006). The rationale was that the assimilation of carbohydrates and optimal tree growth occur only if soil moisture is sufficient to maintain foliage water potential and minimize vapor water deficits (Girardin and Tardif, 2005). The relation was expressed as a linear model and estimation of the model parameters allowed inference of records of mean July DC for six regions (Boreal Plains, Lake Seul, Lake Nipigon, Abitibi Plains west, Abitibi Plains east, and Central Laurentians) of the Boreal Shield in the period from 1769 to 1998. Additionally, the mean July and August temperature for a seventh region, Southern Laurentians (SL) was estimated. the relation. The first criterion may be well not lead to significant changes in regression parameters. The accuracy can be tested by several techniques of data-model comparison, such as reduction of error or the product means test. Such methods are detailed elsewhere in this issue. See also
Girardin and Mudelsee (in press), who assessed the calibration accuracy, with positive results.

\section{Models: Wildfire proxy scenarios}

The General Circulation Model ECHAM4 was used for independently simulating temperature and precipitation over 1850 to 2100 . Analyzed were the IPCC's greenhouse gas emission scenarios $\mathrm{A} 2$ and B2 (Solomon et al., 2007). The gridded daily temperature and precipitation data (about 2.8 deg. spatial resolution) were further transformed into simulated DC by an empirical soil-evapotranspiration model (Girardin et al., 2004). These values were projected in the spatial and temporal domains to yield mean July DC for the seven regions. Feeding DC into the calibrated multiple linear regression model produced FireOcc forecasts. The quality of this model-proxy approach was assessed elsewhere (Girardin and Mudelsee, in press) by means of comparison with other model simulations (e.g., CGCM3). In general, the increase in regional precipitation projected toward the end of the $21^{\text {st }}$ century will be insufficient to compensate for increasing temperatures, and insufficient to maintain potential evapotranspiration at current levels, no matter which scenario is considered. Here, we focus on the wildfire risk by statistically analyzing the indirect proxy FireOcc record, which we inferred from the DC reconstructions (1769-1998) and the climate modeling (1999-2100).

\section{Results and conclusions}

Setting a robust threshold to FireOcc (Fig. 2a,c) allows for the identification of extreme fire years. We were interested in how often such years occur. The rate of occurrence was analyzed using kernel functions and mathematical bootstrap simulations (Fig. 2c,d). First, risk of extreme wildfire years was not constant over time but displayed lows and highs (values up to $0.22 \mathrm{yr}^{-1}$ at around 1800 or $0.18 \mathrm{yr}^{-1}$ during the first half of the $20^{\text {th }}$ century). The average risk of extreme wildfire years through the instrumental period (to 1998) was 0.13 $\mathrm{yr}^{-1}$, which means every $7^{\text {th }}$ to $8^{\text {th }}$ year is an extreme year. Predicted future increases depend on the selected emission scenario. Under the "moderate" B2 scenario, risk values for the end of the $21^{\text {st }}$ century are around $0.20 \mathrm{yr}^{-1}$ (Fig. 2d), under A2 they may be as high as $0.28 \mathrm{yr}^{-1}$. Although the statistical uncertainty (confidence band) is substantial, the amount of data (number of extreme years) allows us to conclude that these changes are statistically significant. 
A number of critical points were addressed (see Girardin and Mudelsee, in press) to evaluate the robustness of these findings. First, proxy representativeness is not perfect. For example, influences of spring and autumn DC values have been ignored. Tree ring series pre-processing (removal of long-term physiological growth signals) may also hide long-term climate trends. Second, feedbacks from vegetation, regional climate systems or other forest disturbances, were not accounted for. Third, emission scenarios are technically "guesses" with unquantified, presumably large, error bars. Fourth, extrapolation errors may have affected the FireOcc calibration as well as the climate model. The confidence bands should capture a portion of these uncertainties. On the other hand, selection of statistical parameters in figure 2 is rather uncritical, as a sensitivity analysis showed.

We deliberately use the word "prediction" instead of "projection" because the latter's connotation of an assumptionfree analysis is misleading. Every analysis of future situations necessarily makes assumptions (actualism). The task is rather to quantify and include the error sources into the analyses. In this regard, it is important to evaluate climate model uncertainties. For this objective, the ensemble method is insufficient because it ignores parameterization uncertainties (e.g., hydrological cycle). The bootstrap simulation method (Challenor, 2004) has the potential to include parameterization and also emission uncertainties but its full implementation requires a leap in computing power.

The predicted increases in fire risk may lead to considerable increases in wildfire management costs, offset the influences of elevated temperatures and atmospheric $\mathrm{CO}_{2}$ concentrations on forest and tree productivity, and affect the availability of harvestable trees (Girardin and Mudelsee, in press). More frequent, large wildfires may also become a major factor in our changing climate, owing to greater carbon losses that could feed the warming (Kurz et al., 1995; Flannigan et al., 2006).

\section{Acknowledgements}

We thank Travis Logan for providing ECHAM4 data and Brian Stocks for the photo. Financial support from Canadian Forest Service funds (M.P.G.) is acknowledged. Fire data, software and risk estimates are available from Climate Risk Analysis (www.mudelsee.com).

\section{References}

Girardin, M.P. and Mudelsee, M., in press: Past and future changes in Canadian boreal wildfire activity, Ecological Applications.

Girardin, M.P., Bergeron, Y., Tardif, J.C., Gauthier, S., Flannigan, M.D. and Mudelsee, M., 2006: A 229-year dendroclimatic-inferred record of forest fire activity for the Boreal Shield of Canada, International Journal of Wildland Fire, 15(3): 375-388.

Mudelsee, M., 2006: CLIM-X-DETECT: A Fortran 90 program for robust detection of extremes against a time-dependent background in climate records, Computers and Geosciences, 32(1): 141-144.

Mudelsee, M., Börngen, M., Tetzlaff, G. and Grünewald, U., 2003: No upward trends in the occurrence of extreme floods in central Europe, Nature, 425(6954): 166-169.

Stocks, B.J. et al., 2003: Large forest fires in Canada, 1959-1997, Journal of Geophysical Research, 108(D1): 8149, doi:10.1029/ 2001JD000484.

For full references please consult:

www.pages-igbp.org/products/newsletter/ref2008_2.html

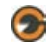

\section{What can data tell us about past climate that is useful for the future? Data management in paleoclimatology}

Nicolas Dittert ${ }^{1}$, D.M. Anderson ${ }^{2}$ and H. Grobe ${ }^{3}$

'MARUM, University of Bremen, Germany; ndittert@uni-bremen.de

2NOAA World Data Center for Paleoclimatology, Boulder, USA

${ }^{3}$ Alfred Wegener Institute for Polar and Marine Research, Bremerhaven, Germany

During the last decades, the number of scientific publications has increased exponentially, as has the number of scientific data sets. No end to the increase is in sight. Under the constraints of an efficient cost-benefit publication system, editors have had to tighten the measures for acceptance of manuscripts (e.g., maximum number of pages, and rigorous selection criteria). Data tables have often been relegated to appendices or supplementary material. With increasing availability of publications through the internet, unique and persistent digital object identifiers (DOIs) have been invented to keep up with the flood of publications. For a long time, scientific data have not been considered within this design strategy. However, the increasing amount of scientific data calls for appropriate archiving and international availability.

Today, this concept is forcefully supported by the Recommendations of the Commission on Professional Self Regulation in Science (1998), the Berlin Declaration on Open Access to Knowledge in the
Sciences and Humanities (2003), the white paper on the free access to scientific data by the Association of Learned and Professional Society Publishers (ALPSP, 2006), and the OECD Principles and Guidelines for Access to Research Data from Public Funding (2007). The vision of the World Data Centre system is the optimized exchange of scientific information leading towards significant and sustainable support of future scientific achievements, as scientific data are perceived as the backbone of discovery. Combined with methods, results, interpretation, and discussion, data sets create a useful scientific publication. However, data have standalone value, and the unconfined availability of (and access to) the data allows for broader use and novel scientific debate.

The value of paleoclimate data to societally relevant problems in climate and environmental change is now well known. To make these data widely available, two remarkable archives have been developed: (1) the PANGAEA ${ }^{\circledR}$ Publishing Network for Geoscientific and Environ-

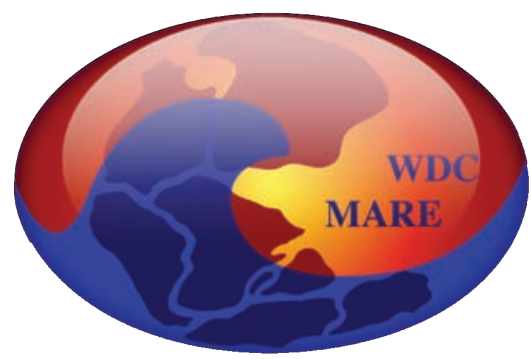

WDC for Paleoclimatology

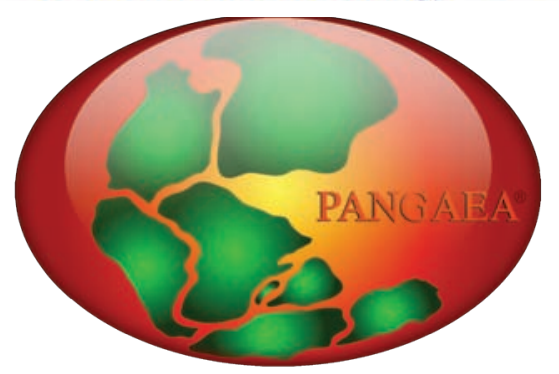

mental Data (Bremerhaven, Germany), which serves as the technical archive for the World Data Center for Marine Environmental Sciences (WDC-MARE), and (2) the NCDC World Data Center for Paleoclimatology WDC-Paleoclimatology in Boulder, USA. WDC-Paleoclimatology describes its mission as providing "the paleoclimate data and information needed to understand and model inter-annual to centennial-scale environmental variability" PANGAEA $^{\circledR}$ campaigns with its long-term and secured archiving structure, highly efficient editorial system, and extensive interoperability with other international data centers and portals. WDC-Paleocli- 